\title{
One-dimensional model of turbulent flow of non-Newtonian drilling mud in non-prismatic channels
}

\author{
Prasanna Welahettige $^{1} \cdot$ Joachim Lundberg ${ }^{1} \cdot$ Dag Bjerketvedt $^{1} \cdot$ Bernt Lie $^{1} \cdot$ Knut Vaagsaether $^{1}$
}

Received: 1 April 2019 / Accepted: 23 August 2019 / Published online: 31 August 2019

(c) The Author(s) 2019

\begin{abstract}
One-dimensional model of non-Newtonian turbulent flow in a non-prismatic channel is challenging due to the difficulty of accurately accounting for flow properties in the 1-D model. In this study, we model the 1-D Saint-Venant system of shallow water equations for water-based drilling mud (non-Newtonian) in open Venturi channels for steady and transient conditions. Numerically, the friction force acting on a fluid in a control volume can be subdivided, in the 1-D drilling mud modelling and shallow water equations, into two terms: external friction and internal friction. External friction is due to the wall boundary effect. Internal friction is due to the non-Newtonian viscous effect. The internal friction term can be modelled using pure non-Newtonian viscosity models, and the external friction term using Newtonian wall friction models. Experiments were carried out using a water-based drilling fluid in an open Venturi channel. Density, viscosity, flow depth, and flow rate were experimentally measured. The developed approach used to solve the 1-D non-Newtonian turbulence model in this study can be used for flow estimation in oil well return flow.
\end{abstract}

Keywords One-dimensional model $\cdot$ Non-Newtonian $\cdot$ Drilling mud $\cdot$ Open channel $\cdot$ Shallow water equations $\cdot$ Fluxlimiter-centred scheme

\section{List of symbols}

A Cross-sectional area $\left(\mathrm{m}^{2}\right)$

$b \quad$ Bottom width (m)

$k_{s} \quad$ Roughness height (m)

$f \quad$ Friction factor $(-)$

$F_{\mathrm{f}} \quad$ Friction force $(\mathrm{N})$

$\mathbf{F}(\mathbf{U}) \quad x$-directional column vector of flux

$g \quad$ Acceleration of gravity $\left(\mathrm{m} \mathrm{s}^{-2}\right)$

$h \quad$ Flow depth (m)

$k \quad$ Flow consistency index $\left(\mathrm{Pa} \mathrm{s}^{n}\right)$

$k_{1} \quad$ A constant (-)

\section{Knut Vaagsaether}

knut.vagsather@usn.no

Prasanna Welahettige

prasanna.welahettige@usn.no

Joachim Lundberg

Joachim.Lundberg@usn.no

Dag Bjerketvedt

Dag.Bjerketvedt@usn.no

Bernt Lie

Bernt.Lie@usn.no

1 Faculty of Technology, University of South-Eastern Norway, Porsgrunn, Norway $k_{2} \quad$ A constant (-)

$k_{M} \quad$ Manning roughness factor (-)

$k_{n} \quad$ Unit corrector, $\left(\mathrm{m}^{1 / 3} \mathrm{~s}^{-1}\right)$

$l \quad$ Free surface width (m)

$n \quad$ Flow behaviour index (-)

$R_{e} \quad$ Reynold number (-)

$R_{\mathrm{h}} \quad$ Hydraulic radius (m)

$S \quad$ Friction slope $\left(\mathrm{m}^{3} \mathrm{~s}^{-2}\right)$

$\mathbf{S}_{R}(\mathbf{U}) \quad x$-directional column vector of wall reflection term

$\mathbf{S}(\mathbf{U}) \quad x$-directional column vector of source term

$u \quad x$-directional velocity component $\left(\mathrm{m} \mathrm{s}^{-1}\right)$

$u_{1}, u_{2} \quad$ Conserved variables

$\mathbf{U}$ Column vector of conserved variable

$V \quad$ Average velocity $\left(\mathrm{m} \mathrm{s}^{-1}\right)$

$\rho \quad$ Density of the fluid $\left(\mathrm{kg} \mathrm{m}^{-3}\right)$

$\tau \quad$ Shear stress $(\mathrm{Pa})$

$\tau_{Y} \quad$ Yield stress $(\mathrm{Pa})$

$\alpha \quad$ Channel angle from the horizontal plane $\left(^{\circ}\right)$

$\dot{\gamma} \quad$ Shear rate $\left(\mathrm{s}^{-1}\right)$

$\theta \quad$ Trapezoidal angle $\left(^{\circ}\right)$

$\eta_{0} \quad$ Viscosity at low rate of shear/ viscosity at yield stress (Pa s)

$\eta_{500} \quad$ Viscosity at shear rate $500 \mathrm{~s}^{-1}$ (Pa s)

$\eta_{\infty} \quad$ Viscosity at high rate of shear (Pa s)

$\lambda \quad$ Relaxation time (s) 


\begin{tabular}{ll}
\hline \multicolumn{2}{l}{ Abbreviation } \\
$e$ & External friction \\
$i$ & Internal friction \\
DF & D Fread \\
FLIC & Flux limiter centred \\
HB & Herschel-Bulkley \\
PC & Pierre Carreau \\
PL & Power law \\
RH & Rainer Haldenwang \\
TVD & Total variation diminishing
\end{tabular}

\section{Introduction}

One-dimensional prediction of non-Newtonian turbulent effect is more challenging than 2-D and 3-D shallow water flow prediction. One-dimensional models are, however, considerably more economical. There can be two types of friction assumptions in non-Newtonian fluids: internal friction due to viscous effect and external friction due to channel boundaries (Jin and Fread 1997, Fread 1988, 1993). External friction from channel walls can, in 1-D modelling, be calculated from the Darcy-Weisbach equation, the Chezy equation, and the Manning formula (Manning 1891; Chow 1959; Akan 2006; Abdo et al. 2018). This is similar to the Newtonian flow friction force from the walls. The Manning formula is the most widely used (Rahman and Chaudhry 1997; Sanders and Iahr 2001; Agu et al. 2017; Welahettige et al. 2018). The open-channel flow friction factor can be expressed as being equivalent to the pipe flow friction factor, pipe diameter being replaced by four times the openchannel hydraulic radius for Newtonian flow (Chow 1959; Akan 2006; Alderman and Haldenwang 2007). $f=16 / R e^{*}$ is widely used for the rectangular-channel friction factor for a fully developed non-Newtonian laminar flow. $R_{e}^{*}$ is here a generalization of the Reynolds number (Kozicki and Tiu 1967; Burger et al. 2010). There are in general two types of laminar flow regimes in open-channel flow when $R e<500$, and there are small flow depth and small flow velocities: subcritical laminar and supercritical laminar (Chow 1959). Laminar flows are, however, not significant in large-scale flow applications such as oil well return open-channel flow. Turbulent flow is, however, easily propagated due to high flow rates, wall friction, shape of the channel, and viscous forces.

Internal friction from the non-Newtonian fluid flow in open channels can be modelled using pure non-Newtonian flow models such as the power law (Kozicki and Tiu 1967) and the Herschel-Bulkley model (Jin and Fread 1999; Haldenwang 2003). A number of non-Newtonian turbulent open-channel friction factors have been reviewed by Alderman and Haldenwang (2007). According to the dip phenomenon (Stearns $1883)$, maximum velocity in open channels takes place below the free surface in narrow channels with an aspect ratio of $l / h<5$ (Sarma et al. 1983; Yang et al. 2004; Bonakdari et al. 2008; Absi 2011). Where the bed is rough, the curvature of the velocity distribution increases due to the weak secondary motion from the lateral solid walls, transporting low momentum fluid to the central section (Nezu et al. 1994). The dip phenomenon is not widely used in 1-D modelling due to the difficulty of the formulation. Rectangular channels are very common in 1-D shallow water equation modelling. Trapezoidal open channels are less widely modelled because the trapezoidal shape of the cross section increases the complexity of the equations. Mozaffari et al. (2015) and Liu et al. (2017) have studied time-dependent properties of non-Newtonian fluid.

Supercritical and subcritical flow regimes can, where the channel is horizontal, be observed occurring simultaneously before and after the Venturi region (Welahettige et al. 2017a, b). Higher-order Godunov-type numerical schemes are recommended for solving the open-channel conservation equations due to the following issues: unsteady hydraulic jump propagation, to avoid negative flow depth (reduce numerical viscosity) and maintain stability at dry or near-dry conditions (Sanders and Iahr 2001; Kurganov and Petrova 2007). The flux-limitercentred (FLIC) scheme using the source term splitting method is well suited to solving 1-D shallow water equations (Welahettige et al. 2018). The FLIC scheme is used to calculate the interface fluxes, the lower-order flux and higher-order flux being combined using a flux limiter function. The higher-order flux comes from the Richtmyer scheme, and the lower-order flux from the first-order-centred (FORCE) scheme, which is a combination of the Lax-Friedrichs and the Richtmyer schemes (Toro 2009).

A large number of studies have been conducted into drilling mud pipe flow (Alderman et al. 1988; Bailey and Peden 2000; Maglione et al. 2000; Piroozian et al. 2012; Livescu 2012; Aslannezhad et al. 2016). There are, in contrast, fewer published studies on drilling mud flow in open channels. The primary objective of this research paper is therefore to validate the 1-D numerical model for drilling mud in open non-prismatic channels flow using experimental results. The developed models will be used in the future for well return flow estimation. Model accuracy depends on the validity of the assumptions. Pure non-Newtonian models are combined with the turbulence models to provide a source term for the centred total variation diminishing (TVD) scheme. Viscosity, density, flow depth, and flow rates are measured experimentally at the laboratory scale for a water-based drilling mud.

\section{Numerical schemes}

The shear rate variation from the bottom wall to the free surface can be formulated in 3-D and 2-D models by the velocity gradient $\dot{\gamma}_{z x}=\partial u / \partial z$ where $z \leq h$. Here, $\dot{\gamma}_{z x}$ is the 
shear rate in the $x$-direction perpendicular to the $z$-direction. It is, however, challenging to include the shear rate into a 1-D model. Three main shear stresses apply in 3-D fluid flow in the $x$-direction: a linear elongation deformation $\left(\tau_{x x}\right)$ and two shear linear deformations $\left(\tau_{z x}\right.$ and $\left.\tau_{y x}\right)$. Linear elongation deformation can, assuming incompressible liquid properties, be neglected (Versteeg and Malalasekera 2007). Bottom surface velocity becomes zero under the no-slip condition, and shear stress from the air is negligible at the free surface. There are two strong velocity gradients for Newtonian fully developed turbulent open-channel flow: the inner region, which is approximately $20 \%$ of the flow depth, and the outer region (Bonakdari et al. 2008). The dip correction factor can be neglected if the aspect ratio is $>5$ and the velocity profile is similar to the log law for smooth walls (Yang et al. 2004; Absi 2011). The shear stress effect from the side wall from wide, open channels is smaller than the shear stress from the bottom walls, $\tau_{y x} \ll \tau_{z x}$. Therefore, $\tau_{y x}$ can be neglected for 1-D (Longo et al. 2016). The average shear stress and shear rate for 1-D models, based on the assumptions made, can be considered to be $\tau \approx \tau_{z x}$, and $\dot{\gamma} \approx \dot{\gamma}_{z x}$, respectively. The shear stress correlated to the power law (PL), the Herschel-Bulkley (HB), and the Pierre Carreau (PC) model can be given as

$\tau_{\mathrm{PL}}=k \dot{\gamma}^{n}$

$\tau_{\mathrm{HB}}=\tau_{Y}+k \dot{\gamma}^{n}$

$\tau_{\mathrm{PC}}=\dot{\gamma}\left(\eta_{\infty}+\left(\eta_{0}-\eta_{\infty}\right)\left(1+(\lambda \dot{\gamma})^{2}\right)^{\frac{n-1}{2}}\right)$.

The 1-D shallow water equations need to include a modification for the contraction and expansion region of open Venturi channels, to avoid artificial accelerations (Fread 1993; Sanders and Iahr 2001; Welahettige et al. 2018). An additional term has been suggested for the general shallow water equations in our previous study to accurately take into account the non-prismatic effect of the channel walls (Welahettige et al. 2018). The new term is a function of the flow depth and the variation of channel bottom width, $k_{g_{2}} h^{2} g \partial b / \partial x$. For prismatic channels $(\partial b / \partial x=0)$, the shallow water equations are converted to the general shallow water equations. In this study, we, however, attempt to formulate the non-Newtonian friction slope as a separate term for 1-D shallow water equations, $S_{i}$. One-dimensional shallow water equations in Saint-Venant's form for locally trapezoidal channels and for non-Newtonian fluid can therefore be presented as:

$$
\frac{\partial A}{\partial t}=-\frac{\partial(A u)}{\partial x}
$$

$\frac{\partial(A u)}{\partial t}=-\frac{\partial\left(A u^{2}\right)}{\partial x}-\frac{\partial\left(k_{g_{1}} A h\right)}{\partial x} g+k_{g_{2}} h^{2} g \frac{\partial b}{\partial x}+A g \sin \alpha-S_{f}-S_{i}$.
Unlike rectangular channels, the cross-sectional area $(A)$ is not a linear function of flow depth $(h)$ (Fig. 1). The relation between the flow depth and the cross-sectional area can be expressed as (Welahettige et al. 2018)

$h=\frac{-b+\sqrt{b^{2}+4 k_{1} A}}{2 k_{1}}, k_{1}=\frac{1}{\tan \theta}$.

$k_{g_{1}}$ is the ratio between the gravity height of the crosssectional area and the flow depth in the trapezoidal shape. This helps calculate an accurate hydrostatic pressure (Welahettige et al. 2018). $k_{g_{2}}$ is the ratio between the gravity height of the sidewall cross-sectional area and the flow depth. The affected sidewall area is approximately of rectangular shape. Therefore, $k_{g_{2}} \approx 0.5$. However, $k_{g_{1}}$ is a function of $b$ and $h$. Therefore, using a constant value for $k_{g_{1}}$ is not valid. It is always higher than 0.5 (Welahettige et al. 2018):

$k_{g_{1}}=\frac{1}{2}+\frac{h^{2} k_{1}}{6 A}$.

According to the turbulent pipe flow of a non-Newtonian fluid, shear stress can be formulated as a combination of the effect of dynamic viscosity $(\mu)$ and eddy momentum kinematic viscosity $\left(\mu_{t}\right), \tau_{z x}=\left(\mu / \rho+\mu_{t} / \rho\right) \mathrm{d}\left(\rho V_{x}\right) / \mathrm{d} z$ (Douglas et al. 2001; Chhabra and Richardson 2011). This approach can be used for open-channel non-Newtonian turbulent flow. In turbulent flow, wall shear stress is predominant in the laminar region and turbulent eddies are predominant in the turbulent core. Laminar sublayer thickness is, in general, very small in turbulent flow (Versteeg and Malalasekera 2007). The laminar sublayer effect can therefore essentially be described by a pure laminar rheological model, and the turbulent core effect can essentially be described by the Newtonian turbulence model. The Manning formula adds wall friction by considering the hydraulic radius of the channel for the numerical model of the 1-D shallow water equations (Chow 1959). According to our previous study, Manning's turbulence friction model produces good results for open-channel turbulent water flow (Welahettige et al. 2018). The friction slope for the turbulent

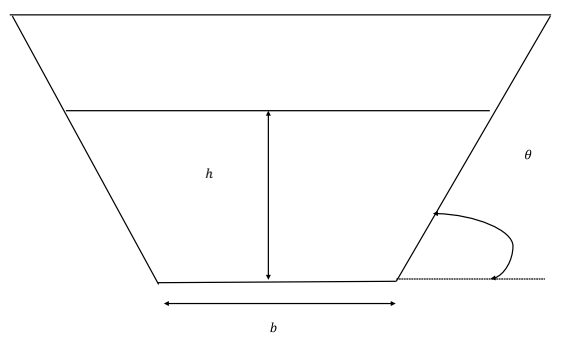

Fig. 1 Channel cross section area: Here, $h, b$, and $\theta$ are flow depth, bottom width, and trapezoidal angle

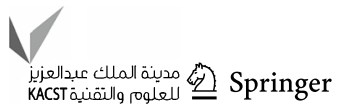


open-channel flow is, according to Manning's formula (Akan 2006; Welahettige et al. 2018),

$S_{e \mathrm{M}}=\frac{k_{\mathrm{M}}^{2} A g}{k_{n}^{2} R_{h}^{4 / 3}}|u| \mathrm{u}$.

The hydraulic radius for trapezoidal channels is

$$
R_{h}=\frac{A}{b+\frac{k_{2}}{k_{1}}\left(-b+\sqrt{b^{2}+4 k_{1} A}\right)}, k_{2}=\frac{1}{\sin \theta} .
$$

The Reynolds number for pipe flow $R e=\rho V D / \eta$ can be converted into an open-channel Reynolds number by replacing $D$ with $4 R_{h}$. $D$ is here the pipe diameter, and $\eta$ is the effective viscosity of a non-Newtonian fluid. According to the Hagen-Poiseuille equation, $8 \mathrm{~V} / \mathrm{D}$ is the shear rate at the wall for Newtonian or non-Newtonian pipe flow (Chhabra and Richardson 2011). For the open channel, the shear rate for non-Newtonian flow is $\dot{\gamma} \approx 2 V / R_{h}$ (Haldenwang 2003). We use this shear rate to describe the shear stress. The shear rate $\dot{\gamma} \approx 2 V / R_{h}$ is valid only for laminar flow. The turbulent effect is, however, included in Manning's formula. Here, we assume that the laminar region is dominated by internal friction and that the turbulent region is dominated by external friction. This assumption is valid in the open channel due to the higher shear rates at the wall boundary and lower shear rates at the free surface. Kozicki and Tiu's (1967) power-law-based Reynolds number, Zhan and Ren's, Albulanga's and Naik's (Alderman and Haldenwang 2007) Bingham plastic-based Reynolds numbers, and Slatter's (1995) and Haldenwang's (2003) Herschel-Bulkley-based Reynolds numbers are widely used for open-channel non-Newtonian flow. Using the same approach, Reynolds numbers for open-channel flow can be derived from the power law, the Herschel-Bulkley, and the Carreau viscosity models. Effective viscosity $\eta=\tau / \dot{\gamma}$ is taken from Eqs. (1)-(3),

$R_{e}=\frac{4 \rho V R_{h}}{\eta}$.

If we assume $\eta_{t} / \rho d\left(\rho V_{x}\right) / \mathrm{d} z \ll \mu / \rho d\left(\rho V_{x}\right) / \mathrm{d} z$ for laminar region channel flow, then the friction force due to the nonNewtonian viscous effect is $F_{i}=\tau\left(b+2 k_{2} k_{g_{1}} h\right) \Delta x$. This is based on the assumption that average shear stress applies to the gravity height of the flow depth in a control volume. The internal friction slope can be introduced as a function of the internal friction factor, $S_{i}=A \rho g f_{i}$. The dimensionless nonNewtonian friction factor can be introduced as

$f_{i}=\frac{\tau\left(b+2 k_{2} k_{g_{1}} h\right)}{\rho\left(b+k_{1} h\right) h g}$.
For a rectangular channel, the non-Newtonian friction factor then becomes $f_{i}=\tau /(\rho g h)$ where $k_{1}=0$ and $k_{2}=0$. Jin and Fread (1997) derived a similar non-Newtonian friction factor for mud fluid in a rectangular open-channel flow. NonNewtonian friction factors for the power law, Herschel-Bulkley, and Carreau fluids can be derived as follows:

$f_{i \mathrm{PL}}=\frac{\left(b+2 k_{2} k_{g_{1}} h\right)}{\rho\left(b+k_{1} h\right) h g} k\left(\frac{2 V}{R_{h}}\right)^{n}$.

$f_{i \mathrm{HB}}=\frac{\left(b+2 k_{2} k_{g_{1}} h\right)}{\rho\left(b+k_{1} h\right) h g}\left(\tau_{Y}+k\left(\frac{2 V}{R_{h}}\right)^{n}\right)$.

$f_{i \mathrm{PC}}=\frac{\left(b+2 k_{2} k_{g_{1}} h\right)}{\rho\left(b+k_{1} h\right) h g}\left(\frac{2 V}{R_{h}}\left(\eta_{\infty}+\left(\eta_{0}-\eta_{\infty}\right)\left(1+\left(\lambda \frac{2 V}{R_{h}}\right)^{2}\right)^{\frac{n-1}{2}}\right)\right)$.

Equations (4)-(5) are solved using the FLIC scheme and Runge-Kutta fourth-order explicit scheme, for rectangular channels of water (without internal friction slope) by Welahettige et al. (2018). The FLIC scheme and Runge-Kutta fourthorder explicit scheme are used for solving the advection term and the source terms, respectively. This method also extends to the 1-D turbulent non-Newtonian fluid. In this study, we implement the FLIC scheme and Runge-Kutta fourth-order scheme for the turbulent non-Newtonian fluid in a trapezoidal shaped channel. Flow rate $Q$ can be given as $Q=A V$, where the average velocity across the cross section is considered to be $u \approx V$. The area perpendicular to the flow direction is a function of time, flow depth, and spatial domain $A=A(t, h, x)$, and the average velocity is a function of time and spatial domain $V=V(t, x)$. The pure advection Eq. (15) is solved with conserved variables $u_{1}=A$ and $u_{2}=A V$. For continuous bottom topography channels, the bottom-width variation effect is highlighted in the TVD solving method used here. This can be compared with the conventional centred TVD solving method, $1 / \Delta x \mathbf{S}_{\boldsymbol{R}}(\mathbf{U})$ (Welahettige et al. 2018). The pure advection term (advection flux and wall reflection effect) is solved first using the centred TVD method.

$\mathbf{U}_{j}^{m+1}=\mathbf{U}_{j}^{m}-\frac{\Delta t}{\Delta x}\left[\mathbf{F}(\mathbf{U})_{j+\frac{1}{2}}^{m}-\mathbf{F}(\mathbf{U})_{j-\frac{1}{2}}^{m}-\mathbf{S}_{\boldsymbol{R}}(\mathbf{U})_{j}^{m}\right]$.

Here,

$\mathbf{U}=\left(\begin{array}{c}A \\ A V\end{array}\right)=\left(\begin{array}{l}u_{1} \\ u_{2}\end{array}\right)$,

$\mathbf{F}(\mathbf{U})=\left(\begin{array}{c}A V \\ A V^{2}+k_{g_{1}} A h g\end{array}\right)=\left(\begin{array}{c}u_{2} \\ \frac{u_{2}^{2}}{u_{1}}+k_{g_{1}} u_{1} h g\end{array}\right)$, 
$\mathbf{S}_{\boldsymbol{R}}(\mathbf{U})=\left(\begin{array}{c}0 \\ k_{g_{2}} h^{2} g \Delta b\end{array}\right)$,

$\mathbf{S}(\mathbf{U})=\left(\begin{array}{c}0 \\ u_{1} g \sin \alpha-\mathrm{S}_{e}-\mathrm{S}_{i}\end{array}\right)$.

For PL, HB, and PC models, the source terms are

$\mathbf{S}(\mathbf{U})=\left(\begin{array}{c}0 \\ u_{1} g \sin \alpha-\mathrm{S}_{e}-S_{i \mathrm{PL}}\end{array}\right) \mathbf{S}(\mathbf{U})=\left(\begin{array}{c}0 \\ u_{1} g \sin \alpha-\mathrm{S}_{e}-S_{i \mathrm{HB}}\end{array}\right)$, and $\mathbf{S}(\mathbf{U})=\left(\begin{array}{c}0 \\ u_{1} g \sin \alpha-\mathrm{S}_{e}-S_{i \mathrm{PC}}\end{array}\right)$, respectively, with their friction slopes, the internal friction slopes being $S_{i \mathrm{PL}}=A \rho g f_{i \mathrm{PL}}, S_{i \mathrm{HB}}=A \rho g f_{i \mathrm{HB}}$, and $S_{i \mathrm{PC}}=A \rho g f_{i \mathrm{PC}}$.

The wall reflection effect $\mathbf{S}_{\boldsymbol{R}}(\mathbf{U})_{j}^{m}$ is solved here as an advection term, due to the simple numerical calculation of the $\partial b / \partial x$ term, and to minimize numerical diffusion (Welahettige et al. 2018). One advantage of using the centred TVD scheme is to avoid the strictly hyperbolic requirement of the partial differential equations. $m$ is here the time index, $m \in\{1,2, \ldots, N\}$. $j$ is the node index in the spatial grid, $j \in\{1,2, \ldots, l\}$. The source terms (gravity effect, external friction, and internal friction) are then solved using an ordinary differential equation (ODE) solver, the explicit Runge-Kutta fourth-order method (Toro 2009). The initial condition for the ODE solver is the solution from the centred TVD scheme. $k_{g_{1}}\left(u_{1}\right), h\left(u_{1}\right), R_{h}\left(u_{1}\right)$, $\mathrm{S}_{e}\left(u_{1}, u_{2}\right), S_{i \mathrm{PL}}\left(u_{1}, u_{2}\right), S_{i \mathrm{HB}}\left(u_{1}, u_{2}\right)$, and $S_{i \mathrm{PC}}\left(u_{1}, u_{2}\right)$ can be derived in terms of conserved variables by substituting $u_{1}$ and $u_{2}$ with $A$ and $A V$.

$\mathbf{U}_{j}^{n+1}=\mathbf{U}_{j, T V D}^{n+1}+\frac{1}{6}\left(\mathrm{~K}_{1}+2 \mathrm{~K}_{2}+2 \mathrm{~K}_{3}+\mathrm{K}_{4}\right)$.

The explicit Runge-Kutta fourth-order method parameters are $\mathrm{K}_{1}=\Delta t \mathbf{S}\left(t^{n}, \mathbf{U}_{j, \mathrm{TVD}}^{n+1}\right), \quad \mathrm{K}_{2}=\Delta t \mathbf{S}\left(t^{n}+\Delta t / 2, \mathbf{U}_{j, \mathrm{TVD}}^{n+1}\right.$ $\left.+\mathrm{K}_{1} / 2\right), \quad \mathrm{K}_{3}=\Delta t \mathbf{S}\left(t^{n}+\Delta t / 2, \mathbf{U}_{j, \mathrm{TVD}}^{n+1}+\mathrm{K}_{2} / 2\right), \quad$ and $\mathrm{K}_{4}=\Delta t \mathbf{S}\left(t^{n}+\Delta t, \mathbf{U}_{j, \mathrm{TVD}}^{n+1}+\mathrm{K}_{3}\right)$.

Non-Newtonian turbulent friction factors available in the literature for open channels are used for comparison purposes. Haldenwang (2003) derived a turbulent flow friction factor for Herschel-Bulkley fluid flow in open channels based on (Slatter 1995) model. Internal and external frictions are combined in Haldenwang's friction factor $S_{e i \mathrm{RH}}$. Haldenwang's friction slope for trapezoidal open channels can be given as

$S_{e i \mathrm{RH}}=\frac{0.165 A V^{2}}{R_{h}\left(2.5 \ln \frac{2 R_{h}}{k_{s}}-76.86 \eta_{500}-9.45\right)^{2}}$.

The source for the Haldenwang model is

$\mathbf{S}(\mathbf{U})=\left(\begin{array}{c}0 \\ u_{1} g \sin \alpha-S_{e i \mathrm{RH}}\end{array}\right)$.
The apparent viscosity of the shear rate is $5001 \mathrm{~s}^{-1}$, $\eta_{500}$, which is a constant. Here, $k_{s}$ is the roughness height and is $15 \mu \mathrm{m}$ in this study, which is similar to the value for steel walls. Fread (1988; Jin and Fread 1997) has derived a friction slope due to internal viscous dissipation with the rheological properties of the power law equation and a yield stress (similar to the Herschel-Bulkley model). This includes a semi-empirical velocity profile. According to Fread's model, the internal friction factor for trapezoidal channels can be presented as

$S_{i \mathrm{DF}}=\left[\frac{\tau_{y} A}{\rho l}\left[1+\left(\frac{\left(\frac{1}{n}+1\right)\left(\frac{1}{n}+2\right) A V l}{\left(0.74+\frac{0.656}{n}\right)\left(\frac{\tau_{y}}{k}\right)^{\frac{1}{n}} A^{2}}\right)^{\frac{1}{n}+0.15}\right]\right]$.

The source for the Fread model is

$\mathbf{S}(\mathbf{U})=\left(\begin{array}{c}0 \\ u_{1} g \sin \alpha-\mathrm{S}_{e}-S_{i \mathrm{DF}}\end{array}\right)$.

Here, $l$ is the free surface width. For trapezoidal channels, $l$ becomes $b+2 k_{1} h$.

In the sequel, PL, HB, PC, Haldenwang, and Fread models are solved by using the FLIC scheme and Runge-Kutta fourth-order method. The only differences are the source terms. We call the models as PL, HB, PC, and Fread where they are combined with Manning's friction.

\section{Experimental setup}

\section{Venturi rig}

The complete flow loop of the rig contains a mud-mixing tank, a mud-circulating pump, an open Venturi channel, and a mud return tank. See Figs. 2 and 3. The sensing instruments in the setup are a Coriolis mass flow meter, pressure transmitters, temperature transmitters, and ultrasonic level transmitters. Chhantyal et al. (2017) and Agu et al. (2017) also conducted experiments using the same experimental setup. Level transmitters are located along the central axis of the channel and can be moved along the central axis. The accuracy of the Rosemount ultrasonic 3107 level transmitters is $\pm 2.5 \mathrm{~mm}$ for a measured distance of less than $1 \mathrm{~m}$ (Welahettige et al. 2017b). The accuracy of temperature transmitter is $\pm 0.19{ }^{\circ} \mathrm{C}$ at $20{ }^{\circ} \mathrm{C}$. The accuracy of Coriolis mass flow meter is $\pm 0.1 \%$. All the experimental values presented in this paper are averaged values of level sensor readings taken throughout a period of $5 \mathrm{~min}$ at each location. The channel inclination can be changed. A negative channel inclination ( $\alpha$ angle) indicates a downward direction. The 


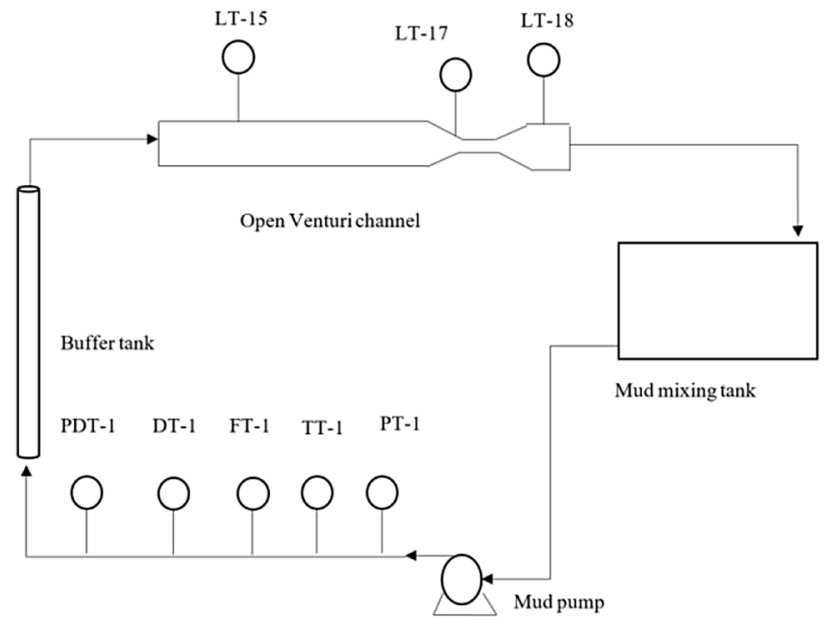

Fig. 2 Flow loop of the experimental setup: $L T$ level transmitter, $P T$ pressure transmitter, $T T$ temperature transmitter, $D T$ density transmitter, and PDT differential pressure transmitter. The level transmitters are possible to move along the central axis of the channel

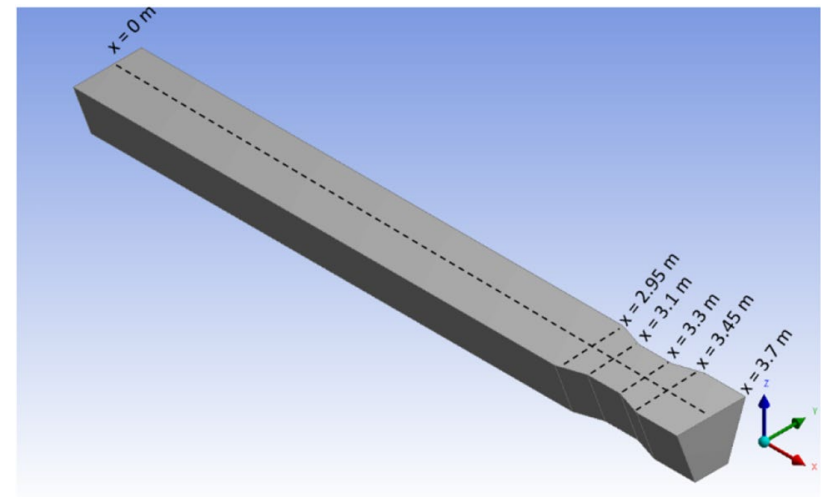

Fig. 3 Dimension of the trapezoidal channel; $x=0 \mathrm{~m}$ is at the inlet of the channel. The Venturi region is $x=2.95 \mathrm{~m}$ to $x=3.45 \mathrm{~m}$. The bottom depth is $0.2 \mathrm{~m}$ for $0 \mathrm{~m}<x<2.95 \mathrm{~m}$ and $3.45 \mathrm{~m}<x<3.7 \mathrm{~m}$. The bottom depth is $0.1 \mathrm{~m}$ for $3.1 \mathrm{~m}<x<3.3 \mathrm{~m}$. The trapezoidal angle is $70^{\circ}$ (Welahettige et al. 2017b)

dimensions of the trapezoidal channel are shown in Fig. 3; the main flow direction is in the $x$-direction.

\section{Viscosity and density measurements}

The water-based drilling mud used for the experiments contained potassium carbonate as a densifying agent and xanthan gum as viscosifier (Chhantyal 2018). The drilling mud viscosity and density were measured using an Anton Paar MCR 101 rheometer and an Anton Paar DMA 4500 density meter. At the beginning of the experiments, the viscosity meter reached a constant room temperature, $25^{\circ} \mathrm{C}$, within $20 \mathrm{~min}$. The constant temperature was maintained throughout the experimental period. For a fixed shear rate value, 40 measuring points were taken within $800 \mathrm{~s}$. The averages of 40 measuring points were considered in this study. The standard deviation of viscosity is small, $1 \times 10^{-5}$, within the 40 measuring points. This indicates that the rheometer reaches a steady state. The combined uncertainty of viscosity is $0.015 \mathrm{mPa}$ s, which is calculated based on the quantifying uncertainty in analytical measurement (QUAM) method (Ellison et al. 2000). An external Anton Paar Viscotherm VT 2 cooling system has a standard temperature uncertainty of $0.02 \mathrm{~K}$ (Idris et al. 2017). For DMA 4500, the temperature accuracy is $\pm 0.03 \mathrm{~K}$. The uncertainty of density is determined as $0.34 \mathrm{~kg} / \mathrm{m}^{3}$ (Han et al. 2012).

The experimentally measured viscosity data were fitted to Eqs. (1)-(3) based on nonlinear regression techniques: the power law model, the Herschel-Bulkley model, and the Carreau model as shown in Fig. 4. The curve-fitted parameters from Table 1 are used: Herschel-Bulkley model for Haldenwang, Fread, PL, HB, and PC models. The density of the drilling mud is $1336 \mathrm{~kg} \mathrm{~m}^{-3}$. Experimental viscosity measurements are in the range of the rheometer accuracy limit where the shear rate is $100-1500 \mathrm{~s}^{-1}$. A shear rate of less than $100 \mathrm{~s}^{-1}$ shows a significant variation in all the models. The accuracy may not be significant in the open Venturi channel flow where the shear rate is less than $100 \mathrm{~s}^{-1}$ for the fluid we used in the experiment. This is because flow regimes are turbulent and the average shear rate is higher than $1001 \mathrm{~s}^{-1}$. This will be further analysed by comparing PL, $\mathrm{HB}$, and PC model results. The average errors between

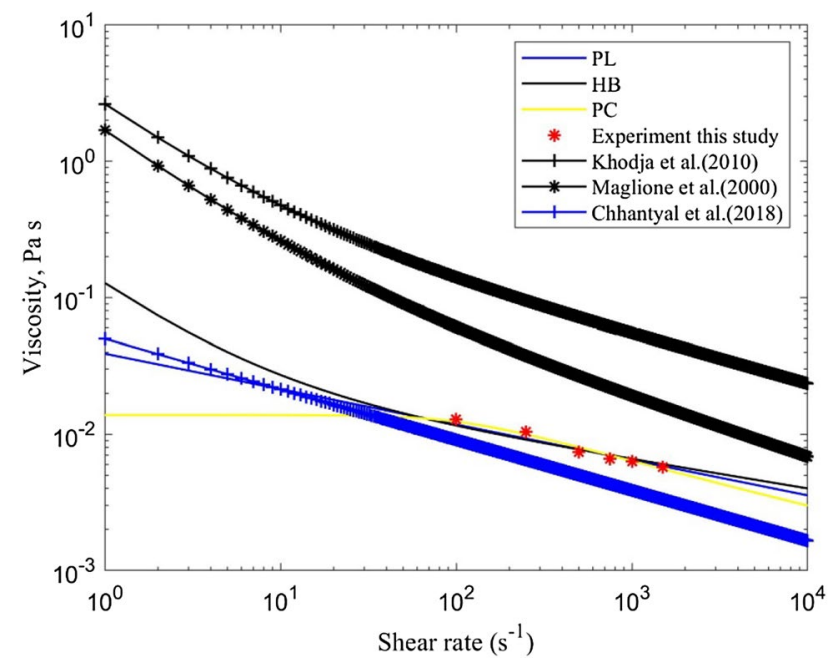

Fig. 4 Shear stress versus viscosity curves for the drilling mud used in this study. The model parameters are from Table 1. Experimental results are from the Anton Paar MCR 101 rheometer. PL, HB, and PC are model-fitted results from the experimental results. Khodja et al.'s (2010), Maglione et al.'s (2000), and Chhantyal's (2018) drilling fluid data are also taken from the literature and used for the comparison 
the calculated and the experimental values are $6.14 \%$, $7.7 \%$, and $4.4 \%$, respectively, for the power law model, the Herschel-Bulkley model, and the Carreau model with $100 \mathrm{~s}^{-1}<\dot{\gamma}<1500 \mathrm{~s}^{-1}$. According to the nonlinear least squares approach in MATLAB R2018a, coefficients are calculated with $95 \%$ confidence bounds. The R-squared values are above 0.95 for all the fitted models. The calculated yield stress is $0.1451 \mathrm{~Pa}$ based on the Herschel-Bulkley model. The yield stress is a small value for the fluid used in this study. The open-channel flow is highly turbulent and has a high Reynolds number; the small yield stress will not significantly influence the flow regimes in the open-channel flow at high turbulence level.

The drilling fluid used in this study shows shear thinning properties in the range of shear rate $100 \mathrm{~s}^{-1}<\dot{\gamma}<1500 \mathrm{~s}^{-1}$ (Fig. 4).

Real and experimental drilling fluids from the literature are used for further comparison in the open-channel flow modelling. Khodja et al.'s (2010) and Maglione et al.'s (2000) real drilling fluids rheology based on the Herschel-Bulkley model is shown in Fig. 4 and Table 1. Chhantyal (2018) used a model drilling mud and the experimental setup used in this study. The model drilling mud rheology was given in terms of the power law model.

\section{Results and discussion}

The rheological parameter and flow parameters used in the simulations are shown in Tables 1, 2, and 3.

\section{Steady results}

Haldenwang, Fread, PL, HB, and PC model results are compared with experimental flow depth along the channel at a steady state (Fig. 5). The results are steady state, reached from an unsteady condition. At the beginning, the drilling fluid enters the empty channel at a constant inlet flow rate. Steady results are achieved after $310 \mathrm{~s}$. The critical flow depth $\left(h_{c}\right)$ is $40 \mathrm{~mm}$ at $0 \leq x \leq 2.95$ and $3.45 \leq x \leq 3.7$, and bottom width and flow depth are the same in the two ranges (Welahettige et al. 2018). According to the Froude number, the flow regime is subcritical $\left(h>h_{c}\right)$ before the Venturi region and supercritical $\left(h<h_{c}\right)$ after the Venturi region (Fig. 5). All the models derived in this study (PL, HB, and PC) give similar results, which indirectly imply that the curve-fitted rheological parameters for each model act in the same way as for the drilling fluid used in this study. The fluid accumulates before the Venturi contraction when the channel is horizontal. Then, due to the channel contraction effect, a hydraulic jump moves upstream before the steady state is reached. The flow depth increases and the velocity decreases due to high energy loss, the friction models giving
Table 1 Rheological parameters of the drilling muds used in this study. Figure 4 shows the related rheology curves
Table 2 Flow parameters used in the simulations: model drilling fluids

\begin{tabular}{lllllll}
\hline & $k\left(\mathrm{~Pa} \mathrm{~s}^{\mathrm{n}}\right)$ & $n$ & $\tau_{y}(\mathrm{~Pa})$ & $\lambda(\mathrm{s})$ & $\eta_{0}(\mathrm{~Pa} \mathrm{~s})$ & $\eta_{\infty}(\mathrm{Pa} \mathrm{s})$ \\
\hline PL & 0.0390 & 0.7402 & - & - & - & - \\
HB & 0.0281 & 0.7882 & 0.1451 & - & - & - \\
PC & - & 0.6443 & - & 0.0095 & 0.01384 & 0.00032 \\
Khodja et al. (2010) & 0.626 & 0.643 & 2.013 & - & - & - \\
Maglione et al. (2000) & 0.334 & 0.576 & 1.360 & - & - & - \\
Chhantyal (2018) & 0.05 & 0.63 & - & - & - & - \\
\hline
\end{tabular}

\begin{tabular}{llll}
\hline & Flow rate $\left(\mathrm{kg} \mathrm{min}^{-1}\right)$ & Inlet velocity $\left(\mathrm{m} \mathrm{s}^{-1}\right)$ & Density $\left(\mathrm{kg} \mathrm{m}^{-3}\right)$ \\
\hline Steady simulations & 433 & 1.3030 & 1336 \\
Unsteady simulations & $480-300$ & $1.444-0.9028$ & 1336 \\
Chhantyal (2018) & 350 & 1.2172 & 1156 \\
\hline
\end{tabular}

\begin{tabular}{llllll}
\hline Source & $k\left(\mathrm{~Pa} \mathrm{~s}^{\mathrm{n}}\right)$ & $n$ & $\tau_{y}\left(\mathrm{~Pa} \mathrm{~s}^{\mathrm{n}}\right)$ & Density $\left(\mathrm{kg} \mathrm{m}^{-3}\right)$ & $\begin{array}{l}\text { Inlet flow } \\
\text { rate }\left(\mathrm{m}^{3}\right. \\
\left.\mathrm{s}^{-1}\right)\end{array}$ \\
\hline Khodja et al. (2010) & 0.626 & 0.643 & 2.013 & 1225 & 0.0056 \\
Maglione et al. (2000) & 0.334 & 0.576 & 1.360 & 1190 & 0.0056 \\
This study & 0.0281 & 0.7882 & 0.1 & 1336 & 0.0056 \\
\hline
\end{tabular}

Table 3 Drilling fluid: Herschel-Bulkley fluid rheological parameters and flow parameter 


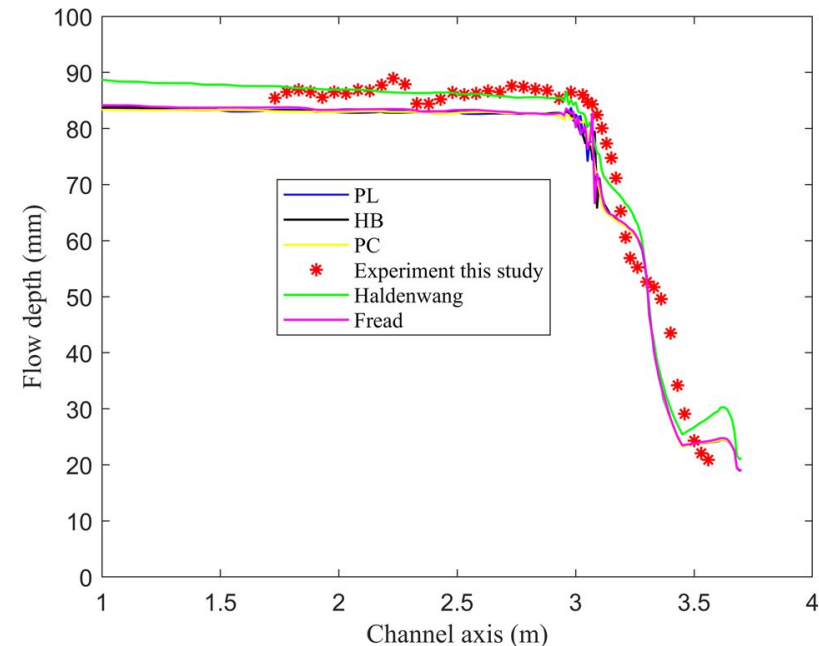

(a)

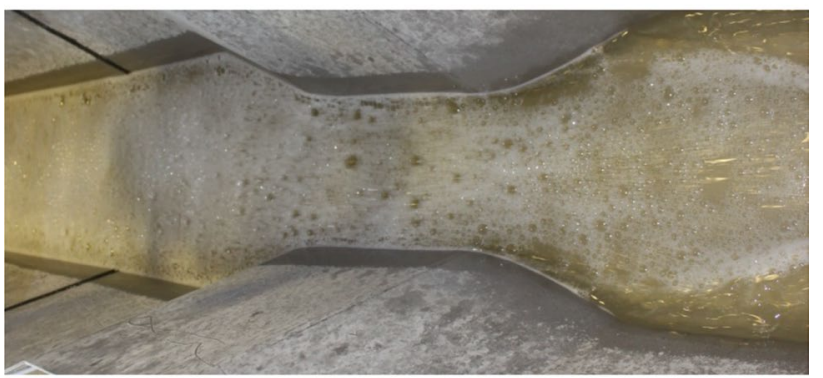

(b)

Fig. 5 A comparison of different friction models for the flow depth variation along the channel axis: The channel inclination is $\alpha=0^{\circ}$. The inlet flow rate is $433 \mathrm{~kg} \mathrm{~min}^{-1}$. a Experimental and simulated flow depth comparison, $\mathbf{b}$ steady-state image of the free surface

higher friction. The Haldenwang model shows higher friction in this case than the PL, HB, and PC models. According to Eq. (17), wall roughness height for the channel is assumed to be $15 \mu \mathrm{m}$, the value for steel walls. This wall roughness value was tested in our previous study (Welahettige et al. 2017b). The PL, HB, and PC models, however, used the Manning roughness factor for steel-smooth walls, which is 0.012. The average deviation from experimental results is $5 \%$ in PL, HB, and PC models at a steady state.

The PL model results are further compared with the Chhantyal's (2018) experimental results (Fig. 6). The rheology of the drilling fluid is given in terms of the power law model. They used a mechanical filter to remove foam, flow depth, therefore being less influenced by foam than in our experimental results. The flow depth difference between experiment and simulation is reduced in the subcritical region when the foam is removed. The PL model gives a good prediction of the Chhantyal's (2018) experimental results. The average deviation from the experimental result is $8 \%$. The yield stress of the fluid is comparatively small. The viscosity of the fluid used in Chhantyal's work is

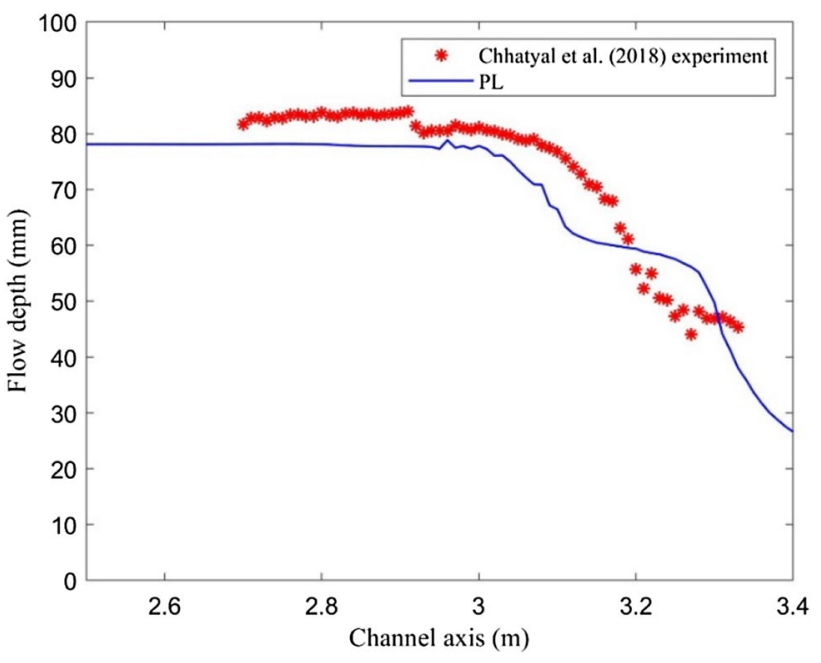

Fig. 6 A flow depth comparison with Chhantyal's (2018) experimental result at a steady state with PL model results. The flow rate is $350 \mathrm{~kg} / \mathrm{min}$ and the channel angle is horizontal. The power law rheological parameters are $k=0.05 \mathrm{~Pa} \mathrm{~s}^{\mathrm{n}}$ and $n=0.63$

$0.04 \mathrm{~Pa} \mathrm{~s}$ at $1 \mathrm{~s}^{-1}$ shear rate, as shown in Fig. 4. The average viscosity value calculated in the simulation is $0.005 \mathrm{~Pa}$ at a steady state, at an average shear rate of $450 \mathrm{~s}^{-1}$. This implies that, in this case, the open-channel flow regimes do not reach the small shear rate ranges. The effect of low shear rates might therefore be insignificant.

\section{Unsteady results}

Figure 7 shows flow depth variation with time for step changes in the channel inlet flow rate. The pump outlet flow mass rate varies between 10 and $40 \mathrm{~kg} \mathrm{~min}^{-1}$ from the set point. At the beginning of the experiment, the channel flow rate is $470 \mathrm{~kg} \mathrm{~min}^{-1}$ at a steady state. Step changes are carried out for the set point of the pump flow rate at time $t=64$ $\mathrm{s}$ and $t=188 \mathrm{~s}$. We show here two-level sensors readings, LT-18 and LT-15. They are fixed at $x=2.12 \mathrm{~m}$ and $x=3.2$ $\mathrm{m}$ from the inlet of the channel, above the free surface along the channel central axis. The PC model and the Haldenwang model results are compared with the experimental readings at the dynamic condition. LT-18 is located after the Venturi region. LT-15 is located before the Venturi region. Even though sudden step changes in the flow rate occur at time $t=64 \mathrm{~s}$ and $t=188 \mathrm{~s}$, the experimental level reading gradually changes flow depth, a complete step change taking more than $40 \mathrm{~s}$. This is despite the pump having a small time constant of $1.6 \mathrm{~s}$. This is due to the time required for fluid to travel from the inlet of the open channel to the level sensor locations, and to unstable wave propagation. Higher flow depth is shown in LT-15 than in LT-18 due to the hydraulic jump formation travelling upstream before the Venturi contraction. The PC model results give a higher accuracy 


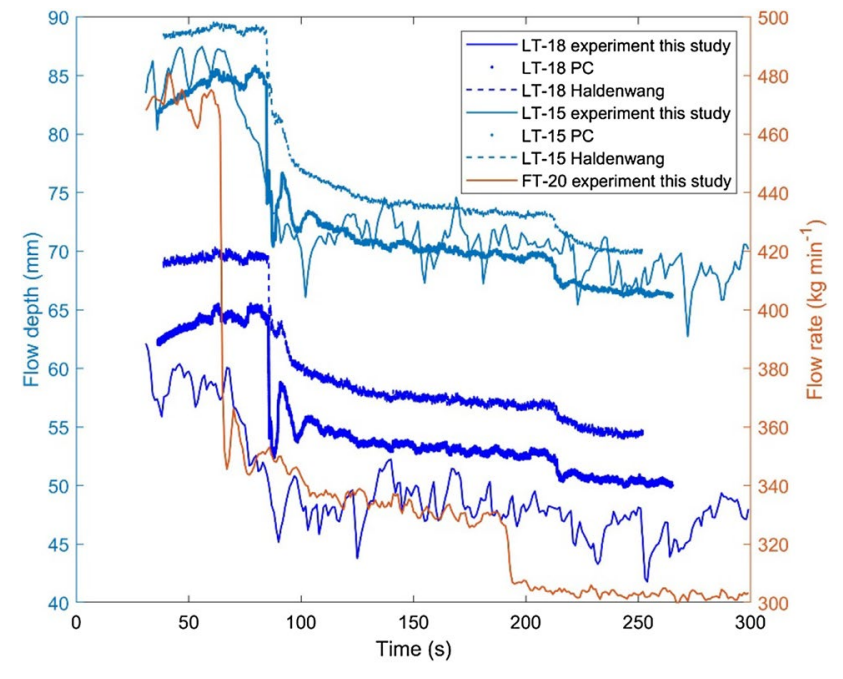

Fig. 7 Flow depth variation with steps change of inlet flow rate: the ultrasonic level sensor is positioned LT-18 and LT-15 at $x=3.20 \mathrm{~m}$ and $x=2.12 \mathrm{~m}$. The channel is at the horizontal angle. The left vertical axis demonstrates the flow depth in $\mathrm{mm}$, and the right vertical axis demonstrates the flow rate in $\mathrm{kg} \mathrm{min}{ }^{-1}$

than the Haldenwang model. The average deviation from the experimental results is 5\% in the PC model.

The accuracy of the models depends on the assumptions used in model development, the curve-fitted rheological parameter, and boundary conditions. An assumption for the 1-D models is that velocity is only considered in the $x$-direction, $V_{x}$. However, the velocity component $V_{z}$ is comparatively small due to free surface movement in the $z$-direction, which is restricted by the surface tension of the fluid and gravitational force, $V_{x} \gg V_{z}$. Channel sidewalls are balanced with the velocity component in the $y$-direction, $V_{x} \gg V_{y}$. However, contraction and expansion of side walls influence and change the direction of the flow path (Welahettige et al. 2017b). The average aspect ratio was 4 in this study. The effect of the dip phenomena was therefore assumed to be small. In this study, the average error of flow depth is 0-6\%.

One of the main advantages of using a 1-D model compared to a 3-D model is less execution time. According to our 3-D CFD simulation of the same case (related to Fig. 5 for water), the 1-D model took $1 \mathrm{~min}$ to execute and the 3-D CFD model took more than $5 \mathrm{~h}$ (Welahettige et al. 2017b).

\section{Effect of source terms}

There are no direct experimental results for the derived friction slopes in this study. The internal and external friction slopes are therefore calculated for different drilling fluids. The three drilling fluids all have different densities and viscosities, the rheology of the fluids being given in the Herschel-Bulkley model. Figure 8 shows a drilling fluid flow depth comparison. The Herschel-Bulkley parameters that

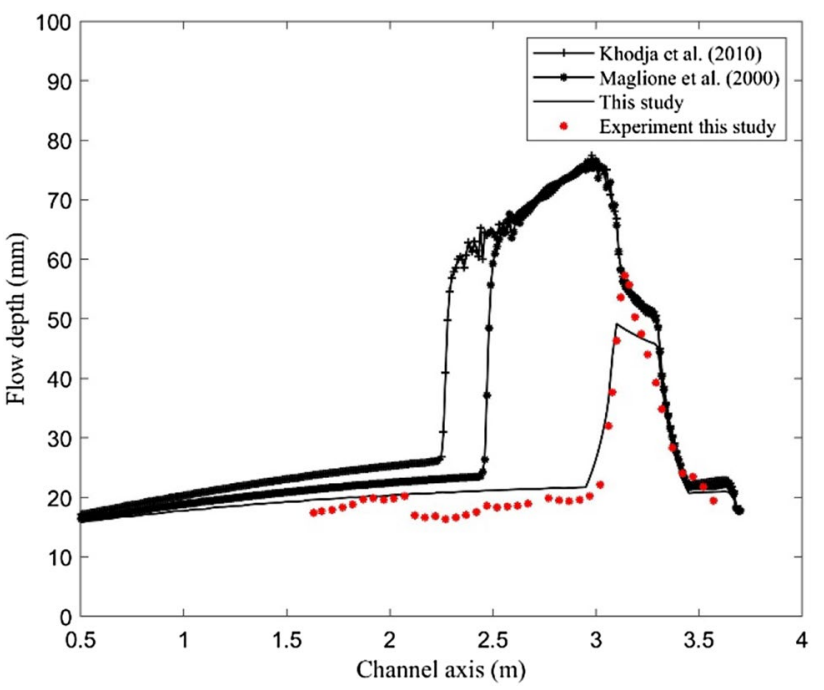

Fig. 8 Flow depth variation for drilling fluids, the rheology based on the Herschel-Bulkley model. The constant inlet flow rate is $0.0056 \mathrm{~m}^{3} \mathrm{~s}^{-1}$, and the channel angle is $-1.7^{\circ}$

specify the drilling fluid rheology are shown in Table 3 . According to the viscosity and shear rate curves, for a given shear rate $\left(>40 \mathrm{~s}^{-1}\right)$, fluid viscosity ranked from the highest to lowest is the Khodja et al.'s (2010) fluid, the Maglione et al.'s (2000) fluid, and the fluid of this study. The inlet flow rate was kept constant at $0.0056 \mathrm{~m}^{3} \mathrm{~s}^{-1}$ for all the fluids. The different densities, however, imply that the inlet mass flow rate is different for each fluid. As explained above, a flow depth that is larger than the critical flow depth is subcritical and contrast supercritical. The Reynolds number is higher than 5300 throughout the channel. Flow regimes therefore become subcritical turbulent and supercritical turbulent. The Reynolds number is calculated from Eq. (10) by substituting effective viscosity for Eq. (3). The channel inclination angle is $-1.7^{\circ}$. Experimental flow depth and the PC model results are well matched for the entire region of the channel. The model drilling fluid used in this study creates an oblique jump at the Venturi throat (Welahettige et al. 2017b). The two other drilling fluids show a hydraulic jump formation at the quasi-steady state. The fluid used in this study, however, has a lower viscosity than the two other drilling fluids and the highest density. This causes lower energy loss and high mass flow rates. The fluid used in this study gives supercritical flow regimes throughout the channel. However, the inlet supercritical flow regimes cannot be maintained for the high viscous fluids (Khodja's and Maglione's drilling fluids), because they generate a hydraulic jump and the level rises to keep the same flow rate at the steady state. Khodja's drilling fluid has a higher density than Maglione's drilling fluid. Khodja's drilling fluid does, however, show greater movement of the hydraulic jump front in the upstream direction due to the higher viscosity of the fluid. The friction

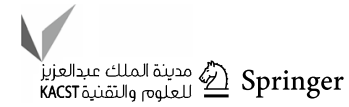




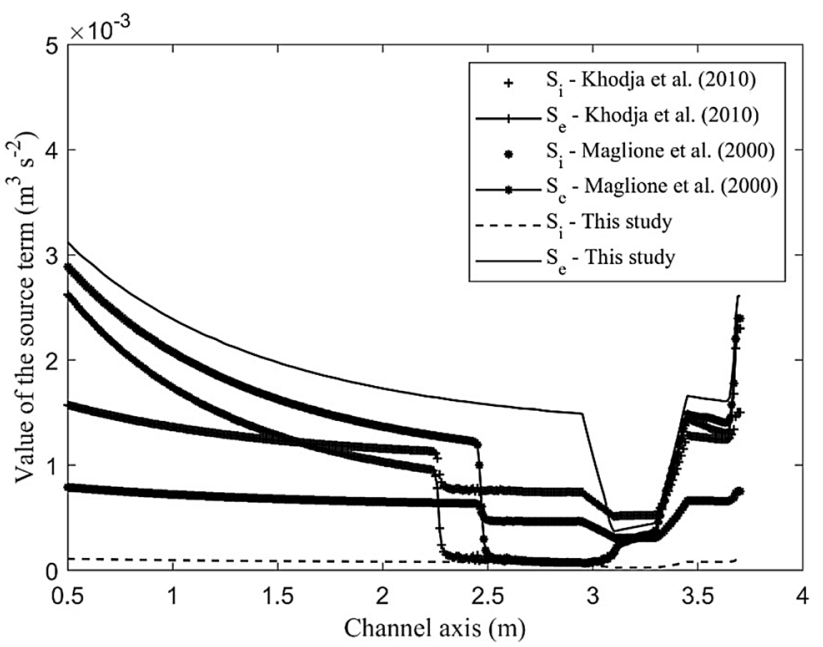

Fig. 9 A comparison of internal friction and external friction for different drilling fluid, the rheology of drilling fluid based on the Herschel-Bulkley fluid. The results are at a steady-state flow in the open Venturi channel, the inlet flow rate is $0.0056 \mathrm{~m}^{3} \mathrm{~s}^{-1}$, and the channel angle is $-1.7^{\circ}$

slopes used to calculate the flow depth in the drilling fluid are studied further in Fig. 9.

The calculated friction slope terms, internal friction slope $\left(S_{\mathrm{i}}\right)$ and external friction slope $\left(S_{\mathrm{e}}\right)$, are shown in Fig. 9. The external friction term is the highest for the lowest viscous fluid, and the internal friction is the lowest for the lowest viscous fluid (the fluid used in this study, which relates to the HB model). Flow depths are supercritical and subcritical before and after the hydraulic jumps. In the subcritical region, the internal friction slope is predominant. In the supercritical region, internal and external friction terms actively contribute to numerical calculations.

\section{Conclusion}

In this study, a 1-D non-Newtonian turbulent model for non-prismatic open-channel flow was developed based on non-Newtonian rheological models and Newtonian turbulence models. The fluid friction term can be divided into two terms: internal friction and external friction. Internal friction is due to non-Newtonian viscosity and external friction is due to wall friction. The higher-order FLIC scheme and Runge-Kutta fourth-order method were used to solve the new 1-D non-Newtonian turbulence models. The approach used to solve the 1-D non-Newtonian turbulence model in this study can be used for flow estimation in oil well return flow. The flow depth prediction error varies from 2 to $8 \%$ in this study, depending on the model's assumptions and experimental results. The internal friction term is predominant in subcritical flow because laminar flow regimes participate in improving the viscous forces, at a steady state. The external friction and internal friction terms contribute to supercritical flow regimes.

Acknowledgements Economic support from the Research Council of Norway and Equinor ASA through Project No. 255348/E30 "Sensors and models for improved kick/loss detection in drilling (Semi-kidd)" is gratefully acknowledged. The authors also gratefully acknowledge Åsmund Hjulstad, Christian Berg, and Sumudhu Karunarathna for sharing knowledge about non-Newtonian rheology.

Funding This work is partially supported by the Research Council of Norway and Equinor ASA through Project No. 255348/E30.

Open Access This article is distributed under the terms of the Creative Commons Attribution 4.0 International License (http://creativeco mmons.org/licenses/by/4.0/), which permits unrestricted use, distribution, and reproduction in any medium, provided you give appropriate credit to the original author(s) and the source, provide a link to the Creative Commons license, and indicate if changes were made.

\section{References}

Abdo K, Riahi-Nezhad CK, Imran J (2018) Steady supercritical flow in a straight-wall open-channel contraction. J Hydraul Res. https ://doi.org/10.1080/00221686.2018.1504126

Absi R (2011) An ordinary differential equation for velocity distribution and dip-phenomenon in open channel flows. J Hydraul Res 49:82-89

Agu CE, Hjulstad Å, Elseth G, Lie B (2017) Algorithm with improved accuracy for real-time measurement of flow rate in open channel systems. Flow Meas Instrum. https://doi.org/10.1016/j.flowmeasin st.2017.08.008

Akan O (2006) Open channel hydraulics. Elsevier, Amsterdam

Alderman NJ, Haldenwang R (2007) A review of Newtonian and nonNewtonian flow in rectangular open channels. Hydrotransport 17:1-20

Alderman N, Ram Babu D, Hughes TL, Maitland G (1988) The rheological properties of water-based drilling fluids. Proc Xth Int Congr Rheol 1:140-142

Aslannezhad M, Khaksar manshad A, Jalalifar H (2016) Determination of a safe mud window and analysis of wellbore stability to minimize drilling challenges and non-productive time. J Pet Explor Prod Technol 6:493-503. https://doi.org/10.1007/s1320 2-015-0198-2

Bailey WJ, Peden JM (2000) A generalized and consistent pressure drop and flow regime transition model for drilling hydraulics. SPE Drill Complet 15:44-56. https://doi.org/10.2118/62167-PA

Bonakdari H, Larrarte F, Lassabatere L, Joannis C (2008) Turbulent velocity profile in fully-developed open channel flows. Environ Fluid Mech 8:1-17. https://doi.org/10.1007/s10652-007-9051-6

Burger J, Haldenwang R, Alderman N (2010) Friction factor-Reynolds number relationship for laminar flow of non-Newtonian fluids in open channels of different cross-sectional shapes. Chem Eng Sci 65:3549-3556. https://doi.org/10.1016/j.ces.2010.02.040

Chhabra RP, Richardson JF (2011) Non-Newtonian flow and applied rheology : engineering applications, 2nd edn. Butterworth-Heinemann, Oxford 
Chhantyal K (2018) Sensor data fusion based modelling of drilling fluid return flow through open channels. University of SouthEastern Norway, Notodden

Chhantyal K, Viumdal H, Mylvaganam S (2017) Soft sensing of nonNewtonian fluid flow in open Venturi channel using an array of ultrasonic level sensors-AI models and their validations. Sensors (Switzerland). https://doi.org/10.3390/s17112458

Chow VT (1959) Open-channel hydraulics. McGraw-Hill, New York

Douglas JF, Gasiorek JM, Swaffield JA (2001) Fluid mechanics, 4th edn. Prentice Hall, Harlow

Ellison SLR, Rosslein M, Williams A (2000) EURACHEM/CITAC Guide CG 4, Quantifying uncertainty in analytical measurement. In: Quantifying uncertainty in analytical measurement, 2 edn. Eurachem

Fread DL (1988) The NWS DAMBRK model: Theoretical background/ user documentation. Hydrol Res Lab, National Weather Service, NOAA

Fread DL (1993) Flow routing. In: Maidment DR (ed) Handbook of hydrology, Chapter 10. McGrawHill, New York, USA, pp $10.6-10.7$

Haldenwang R (2003) Flow of non-newtonian fluids in open channels. Cape Technikon, Cape Town

Han J, Jin J, Eimer DA, Melaaen MC (2012) Density of water (1)+ monoethanolamine (2)+CO2 (3) from (298.15 to 413.15) $\mathrm{K}$ and surface tension of water (1) + monoethanolamine (2) from (303.15 to 333.15) K. J Chem Eng Data 57:1095-1103. https:// doi.org/10.1021/je2010038

Idris Z, Kummamuru NB, Eimer DA (2017) Viscosity measurement of unloaded and $\mathrm{CO} 2$-loaded aqueous monoethanolamine at higher concentrations. J Mol Liq 243:638-645. https://doi.org/10.1016/J. MOLLIQ.2017.08.089

Jin M, Fread DL (1997) One-dimensional routing of mud/debris flows using NWS FLDWAV model. Debris-Flow Hazards Mitigation: Mechanics, Prediction, and Assessment 687-696

Jin M, Fread DL (1999) 1D modeling of mud/debris unsteady flows. J Hydraul Eng 125:827-834

Khodja M, Canselier JP, Bergaya F et al (2010) Shale problems and water-based drilling fluid optimisation in the Hassi Messaoud Algerian oil field. Appl Clay Sci 49:383-393. https://doi. org/10.1016/J.CLAY.2010.06.008

Kozicki W, Tiu C (1967) Non-newtonian flow through open channels. Can J Chem Eng 45:127-134. https://doi.org/10.1002/cjce.54504 50302

Kurganov A, Petrova G (2007) A second-order well-balanced positivity preserving central-upwind scheme for the Saint-Venant system. Commun Math Sci 5:133-160

Liu F, Darjani S, Akhmetkhanova N et al (2017) Mixture effect on the dilatation rheology of asphaltenes-laden interfaces. Langmuir 33:1927-1942. https://doi.org/10.1021/acs.langmuir.6b03958

Livescu S (2012) Mathematical modeling of thixotropic drilling mud and crude oil flow in wells and pipelines-A review. J Petrol Sci Eng 98-99:174-184. https://doi.org/10.1016/J.PETRO L.2012.04.026

Longo S, Chiapponi L, Di Federico V (2016) On the propagation of viscous gravity currents of non-Newtonian fluids in channels with varying cross section and inclination. J Nonnewton Fluid Mech 235:95-108. https://doi.org/10.1016/J.JNNFM.2016.07.007
Maglione R, Robotti G, Romagnoli R (2000) In-situ rheological characterization of drilling mud. SPE J 5:377-386. https://doi. org/10.2118/66285-PA

Manning R (1891) On the flow of water in open channels and pipes. Inst Civil Eng Ireland Trans 20:161-207

Mozaffari S, Tchoukov P, Atias J et al (2015) Effect of asphaltene aggregation on rheological properties of diluted athabasca bitumen. Energy Fuels 29:5595-5599. https://doi.org/10.1021/acs. energyfuels.5b00918

Nezu I, Nakagawa H, Jirka GH (1994) Turbulence in open-channel flows. J Hydraul Eng 120:1235-1237

Piroozian A, Ismail I, Yaacob Z et al (2012) Impact of drilling fluid viscosity, velocity and hole inclination on cuttings transport in horizontal and highly deviated wells. J Pet Explor Prod Technol 2:149-156. https://doi.org/10.1007/s13202-012-0031-0

Rahman M, Chaudhry MH (1997) Computation of flow in openchannel transitions. J Hydraul Res 35:243-256. https://doi. org/10.1080/00221689709498429

Sanders BF, Iahr M (2001) High-resolution and non-oscillatory solution of the St. Venant equations in non-rectangular and non- prismatic channels. J Hydraul Res 39:321-330. https://doi. org/10.1080/00221680109499835

Sarma KVN, Lakshminarayana P, Rao NSL (1983) Velocity distribution in smooth rectangular open channels. J Hydraul Eng 109:270-289

Slatter PT (1995) Transitional and turbulent flow of non-Newtonian slurries in pipes. University of Cape Town, Cape Town

Stearns FP (1883) A reason why the maximum velocity of water flowing in open channels is below the surface. Trans Am Soc Civ Eng $7: 331-338$

Toro EF (2009) Riemann solvers and numerical methods for fluid dynamics-a practical introduction, 3rd edn. Springer, Heidelberg

Versteeg HK, Malalasekera W (2007) An introduction to computational fluid dynamics : the finite method, vol 2. Pearson Education Ltd, Bengaluru

Welahettige P, Lie B, Vaagsaether K (2017a) Computational fluid dynamics study of flow depth in an open Venturi channel for Newtonian fluid. In: Proceedings of the 58th SIMS. Linköping University Electronic Press, Reykjavik, pp 29-34

Welahettige P, Lie B, Vaagsaether K (2017b) Flow regime changes at hydraulic jumps in an open Venturi channel for Newtonian fluid. J Comput Multiph Flows. https://doi.org/10.1177/1757482x17 722890

Welahettige P, Vaagsaether K, Lie B (2018) A solution method for 1-D shallow water equations using FLIC scheme for open Venturi channels. J Comput Multiph Flows 10(4):228-238. https://doi. org/10.1177/1757482X18791895

Yang S-Q, Tan S-K, Lim S-Y (2004) Velocity distribution and dipphenomenon in smooth uniform open channel flows. J Hydraul Eng 130:1179-1186

Publisher's Note Springer Nature remains neutral with regard to jurisdictional claims in published maps and institutional affiliations. 